Bulletin de la Société Royale des Sciences de Liège, Vol. 85, 2016, p. 130 - 139

\title{
The effect of motor imagery on the gross motor skills of children with developmental coordination disorder
}

\author{
Manuscrit reçu le 27 juin 2016 et accepté le 10 juillet 2016 \\ Maryam ASASEH $^{1 *}$, Janet HASHEMI Azar ${ }^{2}$, Ebrahim PISHYARE ${ }^{3}$ \\ ${ }^{1} \mathrm{PhD}$ in psychology and education of exceptional children in Allameh Tabataba'i University \\ ${ }^{2}$ Assistant professor of psychology and education of exceptional children in Allameh Tabataba'i \\ University \\ ${ }^{3} \mathrm{PhD}$ in neuroscience and scientific board of occupational therapy of university of social welfare \\ and rehabilitation
}

\begin{abstract}
Aim: The aim of this study was to evaluate the effectiveness of program design and the evaluation of training effectiveness of motor imagery to improve the motor skills of children with developmental coordination disorder. Methods: In this quasi-experimental study, 16 children were selected to participate in the training program related to motor imagery after the necessary evaluation on children with developmental coordination disorder. The children motor skills was measured by Oseretsky Lincoln test before entering the training program. Motor imagery training program were taught to children with developmental coordination disorder during the eight sessions. Then, gross motor skills of children was re-evaluated. T-test was used to analyze the data after making sure of the reliability and normal distribution of data. Results : The results showed that motor imagery caused a significant difference between pre-test and posttest groups in gross motor skills of children, throwing the ball by children, catching the ball by children, opening and closing hands skills $(\mathrm{P}<0.001)$. This difference was not significant between standing on one foot $(P=0.08)$ and standing on toes $(P=0.351)$. Conclusion: according to the findings of this study, motor imagery training can be helpfully used as a therapy to improve motor skills of children with DCD.
\end{abstract}

Key words: DCD, motor imagery, gross motor skills

\section{Introduction}

Developmental coordination disorder is a developmental disorder that less attention has been paid to it. This disorder is used to describe children without neurological cognitive disease, or mental retardation, has problems with coordination, and these problems affect on his social and academic performance. The range of these difficulties is wide and includes problems in writing, gripping, throwing and jumping up (Deconinck, De Clercq, Van Coster \& Oostra, 2008). DCD occurs in about 5-6\% of children (Gaines, Missiuna, Egan \& McLean, 2008) and its prevalence in boys has been reported 6 times more than girls (Sugden, Kirby \& Dunford, 2008). The performance of children with developmental coordination disorder in daily activities requiring motor coordination is significantly lower than their peers.

\footnotetext{
${ }^{*}$ Email: maryam.asaseh@yahoo.com
} 
Motor coordination problems in these children lead to disorder in the academic achievement or daily activities (Gavin and Toy, 2008) and will create long-term negative consequences, such as academic failure, poor social development, behavior problems, emotional problems and decreased physical fitness (Sugden, Kirby \& Dunford, 2008). These children are weak in the their age-appropriate motor skills and have disorder in gross motor skills (such as jumping, hopping, running) and fine motor skills (such as handwriting, tying shoelaces, utensils and balance) (Kaplan, 2009). Developmental coordination disorder causes negative physical, psychosocial and psychiatric effects as well as will be an introduction to other health problems such as overweight and obesity (Cairney, Schmidt, Veldhuizen, Kurdyak, Hay \& Faught, 2008). One of the models that is provided for the etiology of this disorder states that children with developmental coordination disorder have difficulties in production and had visual-spatial representation of the action which has been known as internal modeling deficit hypothesis (Williams, Thomas, Maruff and Wilson, 2008). This hypothesis has been set based on previous studies in the field of relationship between visual-spatial processes in children with developmental coordination disorder. According to this hypothesis, children with DCD had defect in the proper use of internal models of motor control and there is a relationship between the severity of motor defect with problems in internal modeling (Maruff, Wilson, Trebilcock \& Currie, 1999). In some studies, motor imagery was evaluatedas mental representation of movement in children with developmental coordination disorder and the results showed that there is a relationship between deficiencies in internal modeling and motor imagery (Katschmarsky, Cairney, Maruff, Wilson \& Currie, 2000; Williams et al., 2008). According to this relationship, the evaluation of motor imagery is one of the most important approval procedures of internal modeling deficit hypothesis in children with developmental coordination disorder. The motor imagery is one of improving motor function in individuals. This method as a mental representation of movement has been described without any physical movement (Guillot, Collet \& Dittmar, 2004). The motor imagery is a representation of an active process which an operation is internally and externally generated without any external clear movement in the working memory (Malouin \& Richards, 2010). The motor imagery has led to people motor skills development like physical exercise and generates neurological and physiological responses in the central nervous system and autonomic nervous system (Roosink \& Zijdewind, 2010; Bolliet, Collet \& Dittmar, 2005). Also, the same length of time is spent for the actual implementation of movement or running it mentally (Munzert, Lorey, \& Zentgraf, 2009). Therefore, extensive studies of motor imagery are used as a means of obtaining motor skills Most of these studies have been conducted on athletes and healthy individuals (Heremans, Helsen \& Feys, 2008) and motor imagery has been used to increase motor function retraining of people with disabilities more than two decades (You, Park and Chung, 2001). But to date, little research has been conducted about the ability of motor imagery over the years of growth. In the study of motor imagery in children, argued that motor disability in children is related to the separation of perception and movement. This theory is confirmed by studying specific populations of children such as children with developmental coordination disorder (Gabbard, 2009). In a study, motor 
modeling deficit hypothesis using the mental rotation pattern (hand and words) has been studied. The results show that children with DCD have slower performance and more errors than normal children (Deconinck, De Clercq, Van Coster \& Oostra, 2008). Also has been found, children with DCD use rotational position of the object strategy when performing mental rotation instead of automatic use of motor imagery. Therefore, a person cannot imagine changes from his point of view (Wilson, Maruff, Butson, Williams, Lum \& Thomas, 2004).

Considering to children with DCD have defect in motor imagery and very little researches have been conducted about the effect of motor imagery on improvement of motor skills in children with developmental coordination disorder, the aim of research is to design a training program of motor imagery in children with developmental coordination disorder and the examine the effectiveness of this program on the group.

\section{Method}

In this study, quasi-experimental design with pre-test and post-test was used on a group. The study population consisted of all children with DCD who were referred to the growth neurological clinic. Due to the difficulty and time consuming intervention program, a sample of 16 5-6 year- old children (12 boys and 4 girls) were selected among children of clinic who had been diagnosed by clinic therapists as children with developmental coordination disorder. The diagnostic questionnaire was conducted researcher to ensure correct diagnosis on children with developmental coordination disorder, the diagnostic questionnaire was completed by using coaches, parents and children information at the clinic. After determining the sample, articles related to gross movement of LINCOLN-OSERETSKY test were used as a pre-test to assess the motor skills of children with DCD. The intervention program was developed based on LINCOLN-OSERETSKY test and children do motor imagery according to the 8 sessions of training program. The first three sessions were 60 minutes and next five sessions were 45 minutes. LINCOLN-OSERETSKY test was administered again as a post-test to measure the effectiveness of intervention program. Statistical program of SPSS was used to analyze the data at all stages.

\section{Measurement tools}

The growth motor scale of LINCOLN-OSERETSKY test was used to measure motor skills of children with DCD. The scale is designed to assess motor ability of 5-14 year-old children which is run individually and has 36 articles. In this study, articles related to OSERETSKY gross motor skills (throwing the ball, balancing on one foot, alternately opening and closing the hand, catching the ball and standing on one foot) were used to measure gross motor skills and develop intervention programs. Diagnostic questionnaire is another research tool of DCD. This questionnaire is made by Zahra Salman to diagnose developmental coordination disorder based on the Diagnostic Statistical Manual of Mental Disorders and reliability of the questionnaire is 0.834. (Salman, 2008). The questionnaire consisted of two parts; the first and second parts are related to demographic and developmental coordination disorder respectively, the second part contains 14 questions. If a child gets score in 5 articles, will be known as a child with developmental coordination disorder. 


\section{Data collection method}

The therapeutic program of motor imagery training began after measuring gross motor skills subjects. The researcher tried to communicate with participants in assessment session and prepare them for therapy sessions. In the first training session of motor imagery subject and researcher sat down in front of each other in a quiet room. Researcher asked subject about exercises that did in previous session and named movements with subject and then asked him to do exercises in his mind. The subjects was asked to close his eyes to understand better and do some exercises mentally. The researcher began treatment after making sure that subjects has understood his mean. Researcher read motor articles for subject and asked him to imagine them with closed eyes.10 minutes for each article were given to subjects to imagine and 2 minutes interval were given to subjects after imagining each article.

Stand on one foot: Close your eyes, pull your left foot up in your mind and stand on your right foot without any movement (and vice versa).The researcher verbally repeats articles after each imagination.

Alternatively opening and closing hands: Stretch out your hands forward, hold your hands palms down; punch your right hand, (pointing to the left) punch left hand and open right hand and close your left hand while opening left hand. The researcher verbally asked subjects to do alternatively opening and closing hands with his verbal description to do mentally.

Catching the Ball: A ball thrown from a distance of 3 meters, catch the ball with your right hand (and then your left hand).

Throwing the ball: Take a ball with your left hand in the mind (then right hand), wooden target is placed at a distance of $2.5 \mathrm{~m}$.Put your right foot forward and hit the ball from close your shoulder.

Balancing on toes: Put your hands on your thighs in your mind, pull up your left leg and stand on your right toes (and then on your left toes).

The 3 first sessions were conducted in the same way. But the time of program was reduced to 45 minutes after fourth session that the time was divided between articles.

\section{Findings}

Data from research using SPSS software and descriptive and inferential statistics were analyzed. To check the normality of the dependent variables Kolmogorov-Smirnov test was used. According to the results of this test, data are normally distributed in all stages of investigation. So that, the significant level of Kolmogorov-Smirnov test for pre-test and post-test variables were 0.642 and 0.638 respectively, and Kolmogorov-Smirnov test was not significant for any of the variables. So parametric tests were used to test the hypothesis.

\section{The statistical analysis of hypotheses}

Based on the main hypothesis of this study, motor imagery improve gross motor skills in children with developmental coordination disorder. The descriptive data relating to the main assumptions is presented in Table 1 . 
Bulletin de la Société Royale des Sciences de Liège, Vol. 85, 2016, p. 130 - 139

Table 1. Descriptive data related to the main hypothesis of research

\begin{tabular}{ccccc}
\hline test & number & the average & Standard deviation & Error standard deviation \\
\hline pre-test & 16 & 3.37 & 0.96 & 0.32 \\
post-test & 16 & 12.5 & 2.65 & 0.94 \\
\hline
\end{tabular}

As can be seen in Table 1, it is clear that the average score of motor test of post-test is more than pre-test. To assess the significance of these differences, t-test was used and the results are presented in Table 2.

Table 2: T-test summary about the comparison of gross motor skills scores in pre-test and post-test

\begin{tabular}{cccccc}
\hline Variable & $\begin{array}{c}\text { The difference of the standard } \\
\text { deviation }\end{array}$ & $\begin{array}{c}\text { The mean } \\
\text { difference }\end{array}$ & $\begin{array}{c}\text { Degrees of } \\
\text { freedom }\end{array}$ & T & $\begin{array}{c}\text { Significance } \\
\text { level }\end{array}$ \\
\hline $\begin{array}{c}\text { Gross motor } \\
\text { skills }\end{array}$ & 1.69 & -9.12 & 15 & -13.66 & $<0.001$ \\
\hline
\end{tabular}

Based on the information obtained from this test (Table 2), it is clear that the motor imagery improves the gross motor skills of children with DCD. This improvement was significant ( $\mathrm{P}$ $<0.001)$.

To review secondary research hypotheses, average subscales of motor skills in pre-test and posttest were compared.

To test the hypothesis that a motor imagery improves the movement of throwing the ball in children with developmental coordination disorder, first, the motor skill was measured by Oseretsky test in the pretest and post test and then t-test was used to compare the pre-test and post-test. The results of the mean comparison is presented in Table 3 .

Table 3: T-test summary about the comparison of skills scores of throwing the ball in pre-test and post-test

\begin{tabular}{cccccc}
\hline Variable & $\begin{array}{c}\text { The difference of the } \\
\text { standard deviation }\end{array}$ & $\begin{array}{c}\text { The mean } \\
\text { difference }\end{array}$ & $\begin{array}{c}\text { Degrees of } \\
\text { freedom }\end{array}$ & $\begin{array}{c}\text { T } \\
\text { Significance } \\
\text { level }\end{array}$ \\
\hline $\begin{array}{c}\text { Motor skills of } \\
\text { throwing the ball }\end{array}$ & 0.125 & -2.87 & 15 & -23 & $<0.001$ \\
\hline
\end{tabular}

According to Table 3, the motor imagery improves the throwing the ball in children with DCD. This improvement was significant $(\mathrm{P}<0.001)$.

T-test was used to test the hypothesis that a motor imagery improves the movement of throwing the ball in children with developmental coordination disorder. The results of this test are presented in Table 4. 
Table 4: T-test summary about the comparison of skills scores of catching the ball in pre-test and post-test

\begin{tabular}{cccccc}
\hline Variable & $\begin{array}{c}\text { The difference of the } \\
\text { standard deviation }\end{array}$ & $\begin{array}{c}\text { The mean } \\
\text { difference }\end{array}$ & $\begin{array}{c}\text { Degrees of } \\
\text { freedom }\end{array}$ & T & $\begin{array}{c}\text { Significance } \\
\text { level }\end{array}$ \\
\hline $\begin{array}{c}\text { Motor skills of } \\
\text { catching the ball }\end{array}$ & 0.51 & 3.37 & 15 & -18.44 & $<0.001$ \\
\hline
\end{tabular}

According to Table 4, the motor imagery improves catching the ball in children with DCD. This improvement was significant $(\mathrm{P}<0.001)$.

T-test was used to test the hypothesis that a motor imagery improves the movement of catching the ball in children with developmental coordination disorder. The results of this test are presented in Table 5.

Table 5: T test summary about the comparison of skills scores of alternately opening and closing the hand in pre-test and post-test

\begin{tabular}{cccccc}
\hline Variable & $\begin{array}{c}\text { The difference of the } \\
\text { standard deviation }\end{array}$ & $\begin{array}{c}\text { The mean } \\
\text { difference }\end{array}$ & $\begin{array}{c}\text { Degrees of } \\
\text { freedom }\end{array}$ & $\begin{array}{c}\text { T } \\
\text { Significance } \\
\text { level }\end{array}$ \\
\hline $\begin{array}{c}\text { Motor skills of alternately } \\
\text { opening and closing the } \\
\text { hand }\end{array}$ & 0.64 & -1.87 & 15 & - & $<0.001$ \\
\hline
\end{tabular}

According to Table 5, the motor imagery improves alternately opening and closing the hand in children with DCD. This improvement was significant $(\mathrm{P}<0.001)$.

T-test was used to test the hypothesis that a motor imagery improves the movement of standing on one foot in children with developmental coordination disorder. The results of this test are presented in Table 6.

Table 6: T-test summary about the comparison of skills scores of standing on one foot in pre-test and post-test

\begin{tabular}{cccccc}
\hline Variable & $\begin{array}{c}\text { The difference of the } \\
\text { standard deviation }\end{array}$ & $\begin{array}{c}\text { The mean } \\
\text { difference }\end{array}$ & $\begin{array}{c}\text { Degrees of } \\
\text { freedom }\end{array}$ & $\begin{array}{c}\text { T } \\
\text { Significance } \\
\text { level }\end{array}$ \\
\hline $\begin{array}{c}\text { Motor skills of alternately } \\
\text { opening and closing the } \\
\text { hand }\end{array}$ & 0.64 & -1.87 & 15 & -8.27 & $<0.001$ \\
\hline
\end{tabular}

Based on statistical data (Table 6), the mean difference in pre-test and post-test $(01 / 0=\mathrm{P})$ is not significant and the hypothesis is rejected. In other words, the motor imagery does not improve standing on one foot. 
T-test was used to test the hypothesis that a motor imagery improves the movement of standing on toes in children with developmental coordination disorder. The results of this test are presented in Table 7.

Table 7: T-test summary about the comparison of skills scores of standing on toes in pretest and post-test

\begin{tabular}{cccccc}
\hline Variable & $\begin{array}{c}\text { The difference of the } \\
\text { standard deviation }\end{array}$ & $\begin{array}{c}\text { The mean } \\
\text { difference }\end{array}$ & $\begin{array}{c}\text { Degrees of } \\
\text { freedom }\end{array}$ & $\begin{array}{c}\text { Significance } \\
\text { level }\end{array}$ \\
\hline $\begin{array}{c}\text { Motor skills of } \\
\text { standing on toes }\end{array}$ & 0.604 & -0.25 & 15 & -1 & 0.351 \\
\hline
\end{tabular}

According to Table 7, the mean difference between the pre-test and post-test $(01 / 0=\mathrm{P})$ is not significant and the hypothesis is rejected. In other words, the motor imagery does not improve standing on the toes.

\section{Discussion and Conclusion}

The results of data processing confirm the research hypotheses and positive effect of motor imagery on improvement of gross motor skills in children with developmental coordination disorder. The results of this study are along with other studies such Maruff, Wilson, Trebilcock \& Currie (1999), Wilson, Thomas and Maruff (2002), Wilson, Maruff, Butson, Williams, Lum \& Thomas (2004), Williams, Thomas, Maruff and Wilson (2008) and Deconinck, De Clercq, Van Coster \& Oostra (2008).

Previous studies show that children at the age of five have the ability to use effectively motor imagery to represent movements. Funk, Brugger \& Wilkening, in 2005, using the hands mental rotation task came to the conclusion that 5-6 year-old children use guided motor processes more than adults. But children with DCD have some problems with mental rotation task, motor imagery and the production of right visual and spatial representation of action. Since the internal model has an important role in maintaining the motion control system, its failure will cause some problems in the motor control (Williams, Thomas, Maruff and Wilson, 2008). An important principle in internal modeling in children with developmental coordination disorder is that although the children can imagine the sequence of movements in their minds, have some problems in motor imagery and actual implementation of the action due to external and biological factors defect. It has been shown in various studies that children with DCD have defects in doing tasks related to motor imagery such mental rotation of things rather than control group (Wilson, Thomas and Maruff, 2002) and show unusual time pattern during motor imagery and the severity of defect has direct relationship with disorder (William, Thomas, Maruff and Wilson, 2008; Maruff, Wilson, Trebilcock \& Currie, 1999).

Using the inner pattern of movement plays an important role in predicting movements and motion control. The inner pattern of movement predicts the sensory consequences of movements and controls motor system during the difficult period of mental illness and if there are delays in 
sensory-motor response, such as a delay in the response of the parasympathetic system. The motor imagery as a therapy can potentially consider potential errors of movement's consequences and modify motor commands before the sensory reactions in this way (Wilson, Thomas and Maruff, 2002). As in the main study hypothesis was confirmed, the motor imagery can be used as therapy to improve motor deficits. On the other hand, research has shown that children with DCD have many problems with balance and coordination (Deconinck, De Clercq, Van Coster \& Oostra, 2008) and the individual's skill level is one of the effective factors on the motor imagery. Many researchers have reported that there is a direct relationship between the level of individual experience and skills in implementing and the motor imagery in learning that movement.

Due to the problems of children with developmental coordination disorder in balance and coordination of movements (Deconinck, De Clercq, Van Coster \& Oostra, 2008), the effectiveness of the motor imagery was not significant on two balancing skills of children. At the end of the study after reviewing assumptions, it can be concluded that the main hypothesis was confirmed but secondary hypotheses related to the gross motor skills effectiveness of the motor imagery was not significant. According to the difficulties of most children with DCD in these two areas, much time and more number of sessions are needed to see the motor imagery effectiveness with more tangible changes.

Despite the findings, this study has some limitations like a limited sample size, limited age groups, lack of control group and the use of available sampling methods, so is recommended that researchers consider to these limitations in future research and review the effect of the motor imagery training in other motor disorders.

\section{Notes}

1) Developmental coordination disorder

2) Internal modeling deficit

3) Motor imagery

4) Working memory

5) Mental rotation

6) Lincon osertsky

\section{References}

Bolliet, O., Collet, C., \& Dittmar, A. (2005). Autonomic nervous system activity during actual and mentally simulated preparation for movement. Applied psychophysiology and biofeedback, 30(1), 11-20.

Cairney, J., Schmidt, L. A., Veldhuizen, S., Kurdyak, P., Hay, J., \& Faught, B. E. (2008). Lefthandedness and developmental coordination disorder. Canadian journal of psychiatry. Revue canadienne de psychiatrie, 53(10), 696-699.

Deconinck, F. J., De Clercq, D., Van Coster, R., \& Oostra, A. (2008). Sensory contributions to balance in boys with developmental coordination disorder. Adapted Physical Activity Quarterly, 25(1), 17-35. 
Bulletin de la Société Royale des Sciences de Liège, Vol. 85, 2016, p. 130 - 139

Funk, M., Brugger, P., \& Wilkening, F. (2005). Motor processes in children's imagery: The case of mental rotation of hands. Developmental Science, 8(5), 402-408.

Gabbard, C. (2009). Studying action representation in children via motor imagery. Brain and cognition, 71(3), 234-239.

Gaines, R., Missiuna, C., Egan, M., \& McLean, J. (2008). Interprofessional care in the management of a chronic childhood condition: developmental coordination disorder. Journal of Interprofessional Care, 22(5), 552-555.

Goyen, T. A., \& Lui, K. (2009). Developmental coordination disorder in "apparently normal" schoolchildren born extremely preterm. Archives of disease in childhood, 94(4), 298-302.

Guillot, A., Collet, C., \& Dittmar, A. (2004). Relationship Between Visual and Kinesthetic Imagery, Field Dependence-Independence, and Complex Motor Skills. Journal of Psychophysiology, 18(4), 190.

Heremans, E., Helsen, W. F., \& Feys, P. (2008). The eyes as a mirror of our thoughts:

quantification of motor imagery of goal-directed movements through eye movement registration. Behavioural brain research, 187(2), 351-360.

Kaplan, H. I. (2009). Kaplan and Sadock's comprehensive textbook of psychiatry (Vol. 1). B. J. Sadock, V. A. Sadock, \& P. Ruiz (Eds.). lippincott Williams \& wilkins.

Katschmarsky, S., Cairney, S., Maruff, P., Wilson, P. H., \& Currie, J. (2000). The ability to execute saccades on the basis of efference copy: impairments in double-step saccade performance in children with developmental co-ordination disorder. Experimental Brain Research, 136(1), 73-78.

Malouin, F., \& Richards, C. L. (2010). Mental practice for relearning locomotor skills. Physical therapy, 90(2), 240-251.

Maruff, P., Wilson, P., Trebilcock, M., \& Currie, J. (1999). Abnormalities of imagined motor sequences in children with developmental coordination disorder. Neuropsychologia, 37(11), 1317-1324.

Munzert, J., Lorey, B., \& Zentgraf, K. (2009). Cognitive motor processes: the role of motor imagery in the study of motor representations. Brain research reviews, 60(2), 306-326.

Roosink, M., \& Zijdewind, I. (2010). Corticospinal excitability during observation and imagery of simple and complex hand tasks: implications for motor rehabilitation. Behavioural brain research, 213(1), 35-41.

Salman, Zahra. The impact of perceptual-motor training on improving motor function in Tehran elementary schools children with developmental coordination disorder, thesis for the degree of Doctor of Philosophy, Faculty of Physical Education Tehran University, (2008).

Sugden, D., Kirby, A., \& Dunford, C. (2008). Issues surrounding children with developmental coordination disorder. International Journal of Disability, Development and Education, 55(2), 173-187.

Williams, J., Thomas, P. R., Maruff, P., \& Wilson, P. H. (2008). The link between motor impairment level and motor imagery ability in children with developmental coordination disorder. Human Movement Science, 27(2), 270-285.

Wilson, P. H., Maruff, P., Butson, M., Williams, J., Lum, J., \& Thomas, P. R. (2004). Internal representation of movement in children with developmental coordination disorder: a mental rotation task. Developmental Medicine \& Child Neurology, 46(11), 754-759.

Wilson, P. H., Thomas, P. R., \& Maruff, P. (2002). Motor imagery training ameliorates motor clumsiness in children. Journal of Child Neurology, 17(7), 491-498. 
Bulletin de la Société Royale des Sciences de Liège, Vol. 85, 2016, p. 130 - 139

Yoo, E., Park, E., \& Chung, B. (2001). Mental practice effect on line-tracing accuracy in persons with hemiparetic stroke: a preliminary study. Archives of physical medicine and rehabilitation, 82(9), 1213-1218. 